\begin{tabular}{c} 
TAP CHÍ KHOA HOC ĐÄI HỌC TÂN TRÀO \\
ISSN: $2354-1431$ \\
\hline
\end{tabular}

\title{
GIẢI PHÁP NÂNG CAO TÍNH TÍCH CỰC HỌC TẬP CHO SINH VIÊN NGÀNH CÔNG TÁC XÃ HộI, TRƯờNG ĐẠI HỌC TÂN TRÀO ĐÁP ÚNG ĐÀO TẠO THEO PHƯƠNG THỨC HỌC CHẾ TÍN CHÎ̉
}

Hà Thị Nguyệt $t^{l}$

${ }^{1}$ Truờng Đại học Tân Trào

"Email: nguyethatl41@gmail.com

\section{Thông tin bài viết}

Ngày nhận bài:

20/4/2020

Ngày duyệt đăng:

20/9/2020

Từ khóa:

Tính tích cục hoc tập, tính tích cưc họ tập, họ chế tín chi

\section{Tóm tắt}

Bài báo đưa ra những khái quát chung về thực trạng tính tích cực học tập của sinh viên ngành Công tác xã hội, trường Đại học Tân Trào. Từ đó đề xuất các biện pháp nâng cao tính tích cực học tập của sinh viên ngành Công tác xã hội, đáp ứng yêu cầu của phương thức đào tạo theo học chế tín chỉ, nâng cao chất lượng đào tạo.

\section{Mở đầu}

Trong dạy học nói chung và dạy học ở trường đại học nói riêng, tính tích cực (TTC) của sinh viên (SV) là yếu tố quan trọng hàng đầu quyết định đến quá trình hình thành phẩm chất, năng lực nghề nghiệp của SV và chất lượng đào tạo của các trường đại học nhất là trong điều kiện dạy học của cuộc cách mạng công nghiệp 4.0 và sự chuyển đổi của phương thức đào tạo mới - học chế tín chỉ. Trên cơ sở tìm hiểu thực trạng và những nguyên nhân ảnh hưởng tới tính tích cực học tập của SV ngành Công tác xã hội (CTXH), trường Đại học Tân Trào (ĐHTT) chúng tôi đề xuất các biện pháp giúp SV ngành $\mathrm{CTXH}$ nâng cao tính tích cực học tập, đáp ứng yêu cầu đào tạo trong thời kỳ mới.

\section{Nội dung nghiên cứu}

\subsection{Một số khái niệm công cụ}

2.1.2. Tính tích cực và tính tích cực học tập của sinh viên
Tính tích cực:

- Về mặt thuật ngữ, TTC theo tiếng Latinh là "activies", tiếng Anh có nghĩa là "activity" dùng để chỉ trạng thái hoạt động khi TTC gắn liền với hoạt động. TTC bao hàm tính chủ động, tính chủ định có ý thức của chủ thể.

- Theo từ điển Tiếng Việt, TTC được hiểu theo 2 nghĩa: một là chủ động hướng tới hoạt động nhằm tạo ra những thay đổi, phát triển; hai là hăng hái năng nổ với công việc [4].

- Theo tác giả Thái Duy Tuyên, TTC có mặt tự phát và tự giác. Mặt tự phát của TTC là yếu tố tiềm ẩn bên trong thể hiện tính tò mò, hiếu kỳ, linh hoạt trong đời sống hàng ngày. Mặt tự giác thể hiện ở trạng thái tâm lí, TTC có mục đích và đối tượng rõ rệt do đó có hoạt động để chiếm lĩnh đối tượng đó.

- Trên cơ sở phân tích và tiếp cận các quan điểm về TTC, chúng tôi cho rằng: TTC là yếu tố tinh thần 
bên trong con người thể hiện ở sự chủ động, tự giác, hăng hái, hứng thú và nỗ lực thực hiện hoạt động một cách có hiệu quả.

Tính tích cực học tập của sinh viên:

- Hoạt động học tập của sinh viên ở trường Đại học là quá trình lĩnh hội hệ thống kiến thức khoa học thông qua các môn học dưới sự dẫn dắt của giảng viên nhằm hình thành kiến thức, kỹ năng, kỹ xảo, năng lực nghề nghiệp đáp ứng yêu cầu đào tạo và nhu cầu của xã hội. Như vậy học tập của $S V$ là một dạng hoạt động đặc biệt - hoạt động nhận thức, muốn đạt được kết quả học tập tốt, $\mathrm{SV}$ phải thể hiện tính tích cực học tập (TTCHT).

Có nhiều quan điểm khác nhau về TTCHT, trong bài viết này, chúng tôi đưa ra một số quan điểm sau:

+ Theo tác giả Hà Thế Ngũ̃, TTC hoạt động của người học là sự ý thức được nhiệm vụ học tập từng môn, từng bài nói riêng thông qua việc học tập hăng say, nhiệt tình từ đó tự mình ra sức hoàn thành nhiệm vụ học tập, tự mình khắc phục khó khăn để nắm vững tri thức, kĩ năng mới và tri giác tài liệu một cách tự giác. Tự nắm kiến thức nghĩa là dưới sự hướng dẫn của giáo viên, người học tự mình nắm bản chất của sự vật hị̂n tượng mà tri thức đó phản ánh, biến kiến thức thành vốn riêng của mình thành bộ phận, thuộc tính của nhân cách. [2]

+ Theo Thái Duy Tuyên thì "Tính tích cực học tập của sinh viên là tập hợp các hoạt động nhằm làm chuyển biến vị trí của người sinh viên từ đối tượng tiếp nhận tri thức sang chủ thể tìm kiếm tri thức. để nâng cao hiệu qủa học tập" [3]

+ Tác giả Trần Bá Hoành cho rằng TTC của $\mathrm{SV}$ được biểu hiện ở sự khát khao khoa học, hay nêu thắc mắc, chủ động vận dụng sự tập trung chú ý, sự kiên trì vượt mọi khó khăn để đạt được mục đích. Biểu hiện của TTCHT ở các mức độ khác nhau: tái hiện, tìm tòi, sáng tạo [1].

Như vậy dù diễn đạt khác nhau nhưng tựu chung lại, TTCHT của SV được hiểu là sự chủ động, tự giác, sáng tạo trong quá trình lĩnh hội kiến thức, vận dụng kiến thức của sinh viên trong các hoạt động học tập nhằm hình thành và phát triển nhân cách bản thân.

* Giải pháp nâng cao tính tích cực hoc tập của sinh viên là hệ thống các đề xuất mang tính phù hợp dựa trên thực tiễn các biểu hiện TTCHT của $\mathrm{SV}$ và các yếu tố ảnh hưởng tới TTCHT của $\mathrm{SV}$ nhằm tác động vào sự chủ động, tự giác, sáng tạo của SV trong quá trình học tập, rèn luyện và hoàn thiện hơn nữa các điều kiện thúc đẩy TTCHT của SV nhằm đạt mục tiêu của quá trình đào tạo.

\subsubsection{Phương thức đào tạo theo học chế tín chỉ}

"Phương pháp đào tạo theo hệ thống tín chi” hay gọi tắt là "Hệ thống tín chi” là một phương thức đào tạo tiên tiến trong nền giáo dục của nhiều quốc gia trên thế giới. Nó còn được gọi là học chế tín chỉ để phân biệt với các phương pháp đào tạo ra đời trước nó như học chế niên chế, học chế học phần.

Có nhiều cách hiểu khác nhau về tín chỉ, có những cách hiểu theo khía cạnh định tính hoặc định lượng hoặc nhấn mạnh vào chuẩn đầu ra của sinh viên hay mục tiêu của một chương trình học. Ở Việt Nam, quan điểm về tín chỉ được hiểu phổ biến nhất là quan điểm của học giả người Mỹ gốc Trung Quốc James Quann thuộc Đại học Washington như sau: Tín chỉ học tập là một đại lượng đo toàn bộ thời gian bắt buộc của một người học bình thường để học một môn học cụ thể, bao gồm: (1) thời gian lên lớp. (2) thời gian ở trong phòng thí nghiệm, thực tập hoặc các phần việc khác đã được quy định ở thời khóa biểu. (3) thời gian dành cho đọc sách, nghiên cứu, giải quyết vấn đề, viết hoặc chuẩn bị bài...[5]

Trong bài báo này chúng tôi đồng tình với quan điểm trên bởi phù hợp với các quy định về dạy học theo học chế tín chỉ ở Việt Nam nói chung và ở trường Đại học Tân Trào nói riêng. Theo đó một tín chỉ được quy định bằng 15 tiết học lý thuyết; 30 - 45 tiết thực hành, thí nghiệm hoặc thảo luận; 45 - 90 giờ thực tập tại cơ sở; 45 - 60 giờ làm tiểu luận, bài tập lớn hoặc đồ án, khoá luận tốt nghiệp. Một tiết học được tính bằng 50 phút. Đối với những học phần lý thuyết hoặc thực hành, thí nghiệm, để tiếp thu được một tín chỉ $\mathrm{SV}$ phải dành ít nhất 30 giờ chuẩn bị cá nhân. Như vậy có thể thấy, theo học chế tín chỉ, SV cần phát huy tối đa TTCHT của bản thân mới có thể hoàn thành được các nhiệm vụ học tập và đạt được các mục tiêu của chương trình đào tạo theo tín chỉ.

2.2. Tầm quan trọng của tính tích cực học tập của sinh viên trong quá trình học tập theo phương thức đào tạo học chế tín chỉ

TTCHT của SV trong hoạt động học quyết định chất lượng học tập và chất lượng đào tạo của trường Đại học bởi vì khi $\mathrm{SV}$ tự chủ động, tự giác tập trung cao độ trong học tập, chủ động tham gia các hoạt động học, tìm tòi khám phá nội dung kiến thức, giải quyết các vấn đề phù hợp với khả năng của mình, đề xuất các ý tưởng, nêu lên quan điểm, chính 
kiến khoa học của bản thân và khắc phục những khó khăn trở ngại trên con đường chiếm lĩnh tri thức thì bản thân $\mathrm{SV}$ sẽ có sự trưởng thành về phẩm chất, về năng lực học tập. Hơn ai hết, SV là người quyết định cao nhất đối với sự trưởng thành của chính bản thân mình.

Bên cạnh đó, TTCHT đòi hỏi SV phải luôn tương tác với bạn bè, hội nhóm trong lớp và với $G V$ làm cho không khí học tập trên lớp sôi nổi, kích thích môi trường học tập liên kết giữa các thành viên tham gia, nâng cao chất lượng học tập.

Trong phương thức đào tạo theo học chế tín chỉ, một ưu điểm nổi bật của nó là lấy người học làm trung tâm trong quá trình dạy và học, phát huy được tính chủ động, sáng tạo của người học. Trong phương thức đào tạo theo tín chỉ, tự học, tự nghiên cứu của sinh viên được coi trọng, được tính vào nội dung và thời lượng của chương trình. Người học tự học, tự nghiên cứu, giảm sự nhồi nhét kiến thức của người dạy, và do đó, phát huy được tính chủ động, sáng tạo của người học. Người học là người tiếp nhận kiến thức nhưng đồng thời cũng là người chủ động tạo kiến thức, hướng tới đáp ứng những nhu cầu của thị trường lao động ngoài xã hội. Do đó, tính tích cực của sinh viên trong học tập thể hiện ở hoạt động tự học, tự nghiên cứu là yếu tố cốt lõi quyết định chất lượng của quá trình đào tạo theo học chế tín chỉ. Nếu không phát huy được yếu tố này ở $\mathrm{SV}$ hoặc $\mathrm{SV}$ không thể hiện được yếu tố này trong quá trình học tập theo tín chỉ thì sẽ ảnh hưởng không nhỏ tới kết quả của quá trình học tập, đào tạo.

2.3. Khái quát chung về thực trạng tính tích cực học tập của sinh viên ngành CTXH, trường Đại học Tân Trào

Ngành CTXH là ngành học mới của Trường ĐHTT thực hiện tuyển sinh khóa đầu tiên từ năm học 2017 - 2018, đến nay nhà trường đã tuyển sinh được 3 khóa với tổng số hơn 50 sinh viên, học viên đang theo học. Sinh viên ngành $\mathrm{CTXH}$ chủ yếu ở các tỉnh thuộc khu vực miền núi phía Bắc: Tuyên Quang, Hà Giang, Yên Bái, Lào Cai... với hơn một nửa là người dân tộc thiểu số và ở các khu vực còn nhiều khó khăn về các điều kiện kinh tế - xã hội.

Dựa trên các lí thuyết về TTCHT, chúng tôi xây dựng các biểu hiện TTCHT của SV với nhiều biểu hiện ở 3 thời điểm: I. Trước khi lên lớp, II. Trong quá trình lên lớp, III. Sau khi lên lớp với các mức độ tích cực (mức 1: TTC rất tốt; mức 2: TTC trung bình; mức 3: TTC yếu, kém) và tiến hành khảo sát trên 24 sinh viên chính quy ngành CTXH thuộc Khoa TLGD và $\mathrm{CTXH}$, ĐHTT. Kết quả thể hiện ở bảng sau:

Bảng 2.1: Thực trạng các mức độ biểu hiện tính tích cục học tập của SV ngành CTXH

\begin{tabular}{|c|c|c|c|c|c|c|c|}
\hline \multirow{2}{*}{\multicolumn{2}{|c|}{ Biểu hiện TTC học tập của $\mathrm{SV}$}} & \multicolumn{6}{|c|}{ Mức độ của TTC } \\
\hline & & \multicolumn{2}{|c|}{1} & \multicolumn{2}{|c|}{2} & \multicolumn{2}{|c|}{3} \\
\hline & & SL & $\%$ & SL & $\%$ & SL & $\%$ \\
\hline \multirow{2}{*}{$\begin{array}{l}\text { I: Trước khi } \\
\text { lên lớp }\end{array}$} & 1. Xây dựng kế hoạch học tập rõ ràng & 5 & 20,0 & 13 & 52,0 & 6 & 25,0 \\
\hline & 2. Chuấn bị bài trước khi lên lớp & 4 & 16,0 & 11 & 44,0 & 9 & 37,5 \\
\hline \multirow{7}{*}{$\begin{array}{l}\text { II. Trong } \\
\text { quá trình } \\
\text { lên lớp }\end{array}$} & 3. Đi học đầy đủ, đúng giờ & 12 & 48,0 & 8 & 32,0 & 4 & 16,7 \\
\hline & 4. Chú ý nghe giảng & 10 & 40,0 & 12 & 48,0 & 2 & 8,3 \\
\hline & $\begin{array}{l}\text { 5. Tự giác thực hiện các nhiệm vụ học tập } \\
\text { (ghi chép, thảo luận, phát biểu ý kiến, đặt } \\
\text { câu hỏi) }\end{array}$ & 5 & 20,0 & 9 & 36,0 & 10 & 41,7 \\
\hline & $\begin{array}{l}\text { 6. Hăng hái, sôi nổi trong các hoạt động } \\
\text { học }\end{array}$ & 6 & 24,0 & 10 & 40,0 & 8 & 33,3 \\
\hline & 7. Ôn tập trước khi kiểm tra, thi học phần & 15 & 62,5 & 7 & 28,0 & 2 & 8,3 \\
\hline & $\begin{array}{l}\text { 8. Nghiêm túc, tự giác trong quá trình kiểm } \\
\text { tra, thi }\end{array}$ & 5 & 20,0 & 15 & 60,0 & 4 & 16,7 \\
\hline & 9. Sáng tạo trong quá trình học tập & 2 & 8,0 & 5 & 20,0 & 17 & 70,8 \\
\hline \multirow{2}{*}{$\begin{array}{l}\text { III. Sau khi } \\
\text { lên lớp }\end{array}$} & $\begin{array}{l}\text { 10. Tự học ở nhà, thư viện tương đương } 1 \\
\text { tiết trở lên/môn/tuần }\end{array}$ & 3 & 12,0 & 13 & 52,0 & 8 & 33,3 \\
\hline & 11. Vận dụng kiến thức vào thực tiễn & 2 & 8,0 & 17 & 68,0 & 5 & 20,8 \\
\hline
\end{tabular}


Kết quả ở bảng 2.1 cho thấy TTCHT của SV ngành $\mathrm{CTXH}$ đa số ở mức độ trung bình và yếu kém. TTCHT được thể hiện chủ yếu ở nội dung ôn tập để kiểm tra, thi $(62,5 \%)$ và đi học đầy đủ, đúng giờ $(48,0 \%)$, các biểu hiện ở mức độ trung bình và yếu kém nhất thuộc về tự giác thực hiện các nhiệm vụ học tập, chuẩn bị bài trước khi đến lớp, tự học, sáng tạo trong quá trình học và hăng hái, sôi nổi trong giờ học.

Thực trạng trên chịu sự ảnh hưởng bởi các yếu tố sau đây (Chúng tôi đưa ra 3 mức độ: (1) ảnh hưởng nhiều, (2) ảnh hương ít, (3) Không ảnh huơong). Kết quả thể hiện ở bảng 2.2 :

Bảng 2.2: Các yếu tố ảnh huởng đến TTCHT của SV ngành CTXH

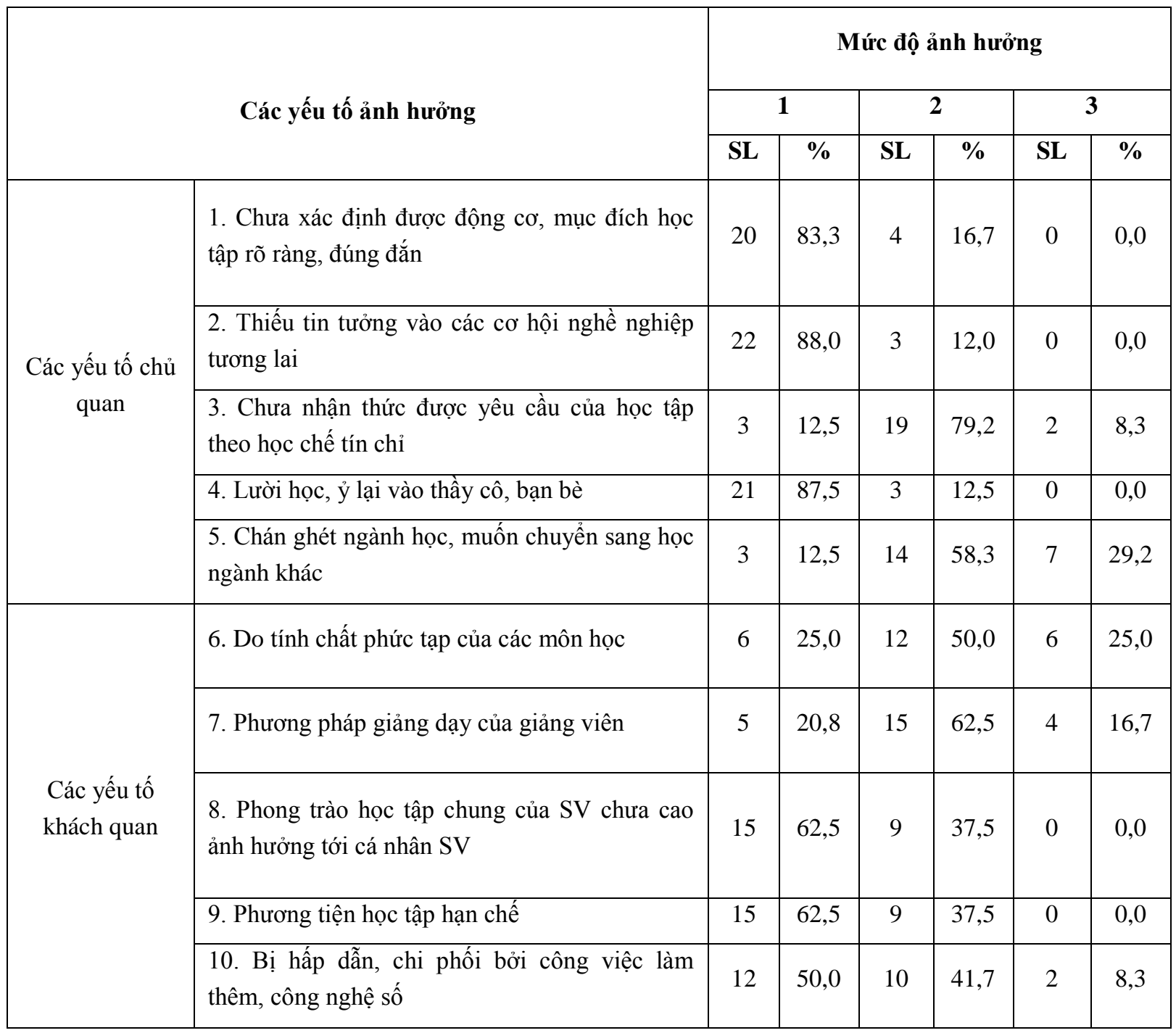

Như vậy, có rất nhiều yếu tố ảnh hưởng tới TTCHT của SV, gồm cả yếu tố chủ quan và khách quan, trong đó các yếu tố ảnh hưởng mạnh nhất tới SV là: Lười học, ỷ lại, trông chờ vào bạn bè̀, thầy cô giáo/ Chưa xác định được mục đích, động cơ học tập đúng đắn/ Thiếu tin tưởng vào các cơ hội việc làm trong tương lai/ Phương tiện học tập còn hạn chế/ Bị chi phối bởi các công việc làm thêm và công nghệ số; các yếu tố khác ảnh hưởng ở mức độ trung bình.

2.4. Một số giải pháp nâng cao tính tích cực học tập cho sinh viên ngành Công tác xã hội, trường Đại học Tân Trào đáp ứng đào tạo theo học chế tín chỉ
Trên cơ sở tìm hiểu thực trạng các biểu hiện TTCHT của $S V$ và các yếu tố ảnh hưởng tới TTCHT của $\mathrm{SV}$ ngành $\mathrm{CTXH}$, chúng tôi đề xuất các biện pháp nâng cao TTCHT cho $\mathrm{SV}$ ngành $\mathrm{CTXH}$, trường ĐHTT đáp ứng đào tạo theo học chế tín chỉ như sau:

\subsection{1. Định hướng SV xác định động cơ, mục} đích học tập đúng đắn

Động cơ học tập là những nhân tố kích thích, thúc đẩy tính tích cực, hứng thú học tập liên tục của người học nhằm đạt kết quả về nhận thức, phát triển nhân cách và hướng tới mục đích học tập đã đề ra. 
Động cơ học tập của SV là yếu tố ảnh hưởng trực tiếp tới TTCHT và kết quả học tập của $\mathrm{SV}$, chất lượng đào tạo của nhà trường. Khi người học có động cơ học tập đúng đắn thì sẽ học tập một cách tích cực, hứng thú và say mê. Ngược lại, việc học tập mang tính chất đối phó, miễn cưỡng thường xuất phát từ động cơ học tập không phù hợp. Cho nên định hướng xây dựng động cơ học tập đúng đắn cho $\mathrm{SV}$ là rất cần thiết để nâng cao chất lượng dạy và học trong nhà trường.

Động cơ học tập của SV bao gồm động cơ bên trong (động cơ hoàn thiện tri thức, động cơ nghề nghiệp, động cơ nâng cao giá trị bản thân) và động cơ bên ngoài (động cơ vật chất, lợi ích...). Động cơ học tập của SV không có sẵn, không bẩm sinh, di truyền và cũng không thể cung cấp hay áp đặt mà có. Động cơ học tập của SV được hình thành dần trong quá trình học tập, rèn luyện. Trong quá trình đó, vai trò của người thầy là vô cùng quan trọng, thầy cô là người định hướng, dẫn dắt $\mathrm{SV}$ chiếm lĩnh tri thức, hình thành nhân cách. Quá trình tương tác của thầy cô bao gồm cả hoạt động giảng dạy và các hoạt động giao tiếp khác là điều kiện quan trọng giúp SV tự hình thành động cơ, mục đích, nhu cầu, hứng thú, ý chí, năng lực, thái độ học tập.

Muốn vậy, các giảng viên giảng dạy các môn học trong chương trình đào tạo ngành $\mathrm{CTXH}$ cần phối hợp chặt chẽ với khoa chuyên môn, xây dựng chương trình đào tạo phù hợp, khoa học, đổi mới và sáng tạo; phương pháp giảng dạy sinh động, trực quan, thực tễ, dễ hiểu; Gần gũi, chia sẻ, định hướng, giúp đỡ $\mathrm{SV}$ chuyên ngành những khó khăn trong học tập cũng như trong cuộc sống; điều chỉnh và tư vấn những nảy sinh về tâm lí, hành vi của $\mathrm{SV}$ trong quá trình đào tạo một cách phù hợp, kịp thời. Đề xuất với nhà trường và thực thi các hoạt động định hướng nghề nghiệp, hợp tác đào tạo nhân lực với các đơn vị sử dụng lao động... nhờ đó, SV sẽ tự xây dựng cho mình được động cơ, mục đích học tập đúng đắn và gắn bó với ngành, nghề đã chọn.

\subsection{2. Đổi mới phương pháp, hình thức tổ chức dạy học của giảng viên theo hướng tích cực hóa hoạt động của SV}

Chương trình đào tạo các ngành ở trường Đại học thường có khối lượng kiến thức lớn, sự liên kết và chuyên sâu giữa các khối kiến thức ở mức độ cao nên nội dung chương trình môn học/ ngành học có tính phức tạp. Rất nhiều môn học mang tính trừu tượng cao nhất là các ngành xã hội. Đó cũng là một trong những rào cản làm cho TTCHT của SV bị giảm sút.
Để kích thích TTCHT của $\mathrm{SV}, \mathrm{GV}$ cần đổi mới phương pháp, hình thức tổ chức dạy học cho phù hợp với các điều kiện dạy học theo tín chỉ và nhu cầu học tập của SV. Muốn vậy GV cần phải:

- Tăng cường sự kết hợp các phương pháp, kỹ thuật dạy học hiện đại theo hướng tích cực hóa hoạt động của người học: Dạy học nêu vấn đề, dự án, thảo luận, thực hành...

- Tăng cường tính thực tiễn trong các bài giảng, liên hệ thực tế sinh động, hấp dẫn và xây dựng nhiều môn học, bài học có tính thống nhất giữa lí thuyết với thực tế tại cơ sở.

- Tăng cường hướng dẫn SV cách tự học cho mỗi bài học đồng thời có sự kiểm tra, giám sát có hiệu quả các hoạt động học tập của SV.

Việc vận dụng các phương pháp, hình thức tổ chức dạy học đa dạng, phù hợp, đảm bảo dễ hiểu giúp SV hiểu bài, yêu môn học, ngành học thì sẽ kích thích SV gắn bó và tính cực thực hiện các hoạt động học tập.

\subsection{3. Đổi mới nội dung, chương trình đào tạo} ngành Công tác xã hội

Chương trình đào tạo là bản thiết kế tổng thể thể hiện toàn bộ các thành phần của quá trình đào tạo, điều kiện, cách thức, quy trình tổ chức, đánh giá các hoạt động đào tạo để đạt được mục tiêu đào tạo. Chương trình đào tạo có ý nghĩa quyết định đến chất lượng đào tạo.

Chương trình đào tạo được điều chỉnh 2 năm/lần theo quy định của Bộ GD và ĐT đảm bảo tính khoa học, tính cập nhật cho phù hợp với nhu cầu xã hội. Trong đào tạo theo học chế tín chỉ, số giờ lý thuyết của các môn học được quy định tối đa là $50 \%$ số giờ lên lớp (không tính các môn học đặc thù), ưu tiên xây dựng các nội dung thực hành (trong giờ học lý thuyết với các hình thức thảo luận, bài tập, xemina...). Các giảng viên chuyên ngành cần tinh giản các nội dung dạy học, xây dựng các môn học trong các khối kiến thức có tính logic với nhau, tăng cường các giờ học trải nghiệm, các giờ thực hành nghề nghiệp tại các cơ sở việc làm bên ngoài thông qua các hình thức hợp tác chuyên môn, làm cho nội dung môn học, ngành học trở nên phong phú, hấp dẫn, kích thích SV tìm tòi, sáng tạo và thể hiện bản thân. Đó cũng là cơ sở giúp giảng viên đổi mới phương pháp và hình thức tổ chức dạy học trong học chế tín chỉ. 


\subsubsection{Thư viện nhà trường cần đảm bảo các điều kiện học tập cho sinh viên}

Thư viện trường Đại học có vị trí quan trọng đóng góp vào đổi mới giáo dục, đào tạo nguồn nhân lực của mỗi cơ sở giáo dục. Thư viện là nơi lưu trữ kho tri thức khoa học lớn với hệ thống sách, báo, tạp chí, tài liệu tham khảo, giáo trình đa dạng với hệ thống các phòng chức năng góp phần quan trọng trong công tác giảng dạy của giảng viên và học tập của sinh viên.

Trong thời đại công nghệ 4.0 đã tạo ra một cuộc cách mạng giáo dục, làm thay đổi nhiều khái niệm cơ bản của giáo dục về dạy học, nghiên cứu. Tham gia quá trình ứng dụng công nghệ thông tin và Internet vào giảng dạy - học tập, nghiên cứu khoa học, thư viện trở thành những trung tâm thông tin - tư liệu thực sự, góp phần đắc lực biến thông tin thành tri thức bằng cách liên kết các nguồn tài nguyên thông tin với nhau, đồng thời mở rộng khả năng đáp ứng nhu cầu tin của mọi đối tượng qua sự hợp tác liên thông và chia sẻ nguồn lực thông tin một cách nhanh chóng, thuận tiện, tiết kiệm cả thời gian và vật chất cho người sử dụng.

Thư viện mở rộng điều kiện học tập cho sinh viên cả về không gian, thời gian và các lĩnh vực tri thức hơn so với khuôn khổ qui định về nội dung, chương trình và kế hoạch đào tạo của nhà trường. Một thư viện trường học tốt sẽ tạo môi trường tự học và tự nghiên cứu, kích thích sự chủ động của người học nhất là trong điều kiện tổ chức dạy học theo tín chỉ, số giờ lí thuyết được rút ngắn, tăng thời gian tự học và thực hành thì chỉ có sự trợ giúp của thư viện mới thể giúp sinh viên hoàn thành được các yêu cầu và mục tiêu học tập.

Việc đào tạo bậc đại học chỉ thực sự có chất lượng khi hoạt động học tập của sinh viên được thực hiện trong cả bốn môi trường: lớp học, thư viện, cơ sở thực nghiệm và môi trường thực tế. Trong đó, thư viện có vai trò quan trọng trong việc rèn luyện tính độc lập, sáng tạo của sinh viên. Người sinh viên phải học một cách thông minh hơn, chủ động hơn qua việc phân tích, tổng luận những tài liệu tra tìm được ở thư viện. Từ đó sẽ xóa bỏ lối học thụ động, khuyến khích việc tự học, tự nghiên cứu, kích thích sự chủ động của sinh viên.

2.4.5. Phát huy vai trò của cố vấn học tập, khoa chuyên môn

Cố vấn học tập là một khái niệm mới xuất hiện trong đào tạo theo học chế tín chỉ có vai trò định hướng, tư vấn, giám sát hoạt động học tập của sinh viên, giúp cho sinh viên nhận thức được tầm quan trọng của quy chế đào tạo, nhận thức được chính xác về quy chế, chương trình đào tạo, phương pháp học đại học, tổ chức hoạt động giúp gắn kết sinh viên với khoa chuyên môn và nhà trường thành một chỉnh thể vận hành thông suốt có sự gắn kết chặt chẽ với nhau.

Để làm tốt vai trò của mình, cố vấn học tập phối hợp cùng khoa chuyên môn thường xuyên tổ chức các buổi sinh hoạt định kỳ về các nội dung chuyên môn về chuyên ngành được đào tạo, thảo luận các phương pháp học tập phù hợp với chuyên ngành đào tạo và phương thức đào tạo theo học chế tín chỉ, xây dựng các kế hoạch dạy học phù hợp đối với từng sinh viên, thảo luận các nội dung mang tính xã hội để hướng sự tập trung của tập thể lớp vào các hoạt động học tập nhằm gắn kết các thành viên trong ngành với nhau, xây dựng phong trào học tập tích cực ở sinh viên. Đồng thời, khoa chuyên môn, cố vấn học tập cần định hướng rõ ràng về mục tiêu học tập của $\mathrm{SV}$ là gi? $\mathrm{SV}$ cần gì để đáp ứng các yêu cầu của nghề nghiệp và nhu cầu xã hội? Thực hiện liên kết, hợp tác với các tổ chức nghề nghiệp bên ngoài để định hướng các cơ hội việc làm cho $\mathrm{SV}$ sau khi ra trường, giúp $\mathrm{SV}$ yên tâm và tin tưởng và ngành học và có động lực học tập. Có như vậy sẽ phát huy được TTCHT của $\mathrm{SV}$.

\subsubsection{Tự bản thân mỗi $\mathrm{SV}$ là người quyết định chất lượng học tập}

Phương thức đào tạo theo học chế tín chỉ đang được áp dụng ở nhiều nước trên thế giới và các trường đại học ở Việt Nam. Đây là phương thức đào tạo lấy người học làm trung tâm, tạo điều kiện giúp SV phát triển bản thân dưới sự định hướng, dẫn dắt của thầy cô giáo. Theo hình thức đào tạo này, thời gian học lý thuyết trên lớp giảm, tăng thời gian thực hành, thực tế và tự học (1 tiết lí thuyết tương đương 2 tiết chuẩn bị bài ở nhà). Để thích nghi được với phương thức đào tạo này, SV phải thay đổi tư duy, phương pháp học tập. Hơn ai hết, chính $S V$ mới là người tự quyết định đến quá trình học tập của bản thân mình, mọi sự định hướng, tác động bên ngoài chỉ là các điều kiện mang tính thúc đẩy hoặc kìm hãm các hoạt động học tập của SV.

Muốn vậy, bản thân SV phải tự xác định được động cơ, mục đích học tập của mình, xây dựng các kế hoạch học tập phù hợp cho từng giai đoạn (môn học/ học kỳ/ năm học)... từ đó quyết định đến nhận thức, thái độ và hành vi của $\mathrm{SV}$ đối với hoạt động học: Học 
để làm gì (mục đích), học vì cái gì (động cơ), tại sao phải học (nhu cầu), học như thế nào (Thái độ). SV phải tự kiểm tra, đánh giá mình ở từng nội dung và mức độ đạt được, từ đó có phương hướng điều chỉnh các vấn đề trong học tập của mình để đạt được mục đích đã đề ra. Nếu bản thân SV không tự xây dựng, bồi đắp, phát triển động cơ, mục đích của mình, không tự thân đánh giá được bản thân mình và tự điều khiển, điều chỉnh hoạt động học tập của mình cho phù hợp thì mọi tác động từ nhà trường, gia đình và xã hội chỉ là vô nghĩa.

\section{Kết luận}

TTCHT của SV là yếu tố then chốt quyết định kết quả học tập, quá trình hình thành phát triển các phẩm chất năng lực - nghề nghiệp của $\mathrm{SV}$ và chất lượng đào tạo của trường Đại học. Qua nghiên cứu về TTCHT của SV ngành CTXH, trường ĐHTT cho chúng ta thấy TTCHT của nhóm SV này còn nhiều hạn chế và bị ảnh hưởng bởi nhiều yếu tố với các mức độ khác nhau. Trên cơ sở đó, chúng tôi đề xuất 6 biện pháp cơ bản có ý nghĩa đối với nhóm SV này để nâng cao TTCHT của $S V$ chuyên ngành $\mathrm{CTXH}$, giúp SV gắn bó với nghành, nghề và nâng cao chất lượng đào tạo của trường ĐHTT.

\section{REFERENCES}

1. Tran Ba Hoanh (2006), Innovating teaching methods, curriculum and textbooks, Pedagogical University Publishing House, Hanoi

2. Ha The Ngu - Dang Vu Hoat (1988), Academic Education 1.2, Educational Publishing House, Hanoi

3. Thai Duy Tuyen (2001), Modern Education, VNU Publishing House

4. Nguyen Nhu Y (editor) (1996), Vietnamese Common Dictionary, Educational Publishing House

5. https://en.wikipedia.org

\section{SOLUTIONS TO IMPROVE THE POSITIVE ATTITUDE IN LEARNING FOR STUDENTS IN SOCIAL WORK MAJOR AT TAN TRAO UNIVERSITY TO MEET TRAINING BY CREDIT LEARNING MODE}

Article info

Recieved:

17/2020

Accepted:

20/9/2020

Keywords:

Positive attitude

learning, positive

attitude, credit learning

mode

\begin{abstract}
The article provides general overview of the reality of positive attitude in learning of students in Social work major at Tan Trao University. Since, the article proposes some methods to improve the positive attitude in learning for students and meet the requirements of training by credit learning mode to improve the quality of training.
\end{abstract}

